\title{
Natural history of preclinical IDDM in high risk siblings
}

\author{
M. Knip ${ }^{1}$, P. Vähäsalo ${ }^{1}$, J. Karjalainen ${ }^{1}$, R. Lounamaa ${ }^{2}$, H. K. Åkerblom ${ }^{3}$ and the Childhood Diabetes \\ in Finland Study Group* \\ ${ }^{1}$ Department of Pediatrics, University of Oulu, Oulu, Finland \\ ${ }^{2}$ Department of Epidemiology, the National Public Health Institute, Helsinki, Finland \\ ${ }^{3}$ The Children's Hospital, II Department of Pediatrics, University of Helsinki, Helsinki, Finland
}

Summary To learn more about the preclinical phase of IDDM we observed for a median period of 46.5 months (range 0.5-69 months) a group of 57 siblings positive for ICA and/or IAA when first screened within 6 months of the diagnosis of the proband. Sequential blood samples and IVGTTs were obtained at intervals of $6-12$ months. Seventeen siblings $(29.8 \%$ ) presented with IDDM during the observation period. The duration of the known preclinical period ranged from 0.5 to 51 months (median 29 months). The converters were younger than the other siblings $(P<0.05)$ and had higher initial ICA levels $(P<0.01)$. In addition they had a lower FPIR in the first IVGTT $(P<0.001)$. On all subsequent tests the converters had higher ICA levels and a lower FPIR ( $P<0.05$ or less), a lower glucose elimination rate from the third test onwards $(P<0.01$ or less $)$ and higher IAA levels at 3 years
$(P<0.05)$. Some variation could be observed in the FPIR in the converters with an initial increase and subsequent decrease $(P<0.05$ for both). Their levels of complement-fixing ICA increased up to 18 months $(P<0.05)$ and IAA levels up to 3 years $(P<0.01)$. Those high risk siblings who progress to clinical IDDM are characterized by young age, strong and increasing signs of islet-cell specific autoimmunity, reduced insulin secreting capacity and emerging glucose intolerance. The present observations seem to be incompatible with the hypothesis of beta-cell destruction occurring at a constant, predictable rate. [Diabetologia (1994) 37:388-393]

Key words Preclinical IDDM, islet cell antibodies, early insulin response, glucose elimination rate.
Insulin-dependent diabetes mellitus (IDDM) is now perceived as an autoimmune disease characterized by progressive beta-cell destruction during an asymptomatic preclinical phase $[1,2]$. The duration of this preclinical phase apparently varies considerably, since the disease may be diagnosed both in infancy and in old age

\footnotetext{
* See Acknowledgements
}

Received: 14 July 1993

and in revised form: 1 November 1993

Corresponding author: Dr. M. Knip, Department of Pediatrics, University of Oulu, SF-90220 Oulu, Finland

Abbreviations: IDDM, Insulin-dependent diabetes mellitus; ICA, islet cell antibodies; IAA, insulin antibodies; IVGTT, intravenous glucose tolerance test; FPIR, first phase insulin response; JDF, Juvenile Diabetes Foundation
$[3,4]$. The highest incidence occurs in children, with a classic peak at puberty [5], although recent data from Finland indicate that this pubertal peak is reaching a plateau [6].

It has been suggested that there is a linear loss of beta-cell function in the preclinical period [7] and that the length of time until a high risk subject presents with clinical diabetes can be predicted with a dual parameter model based on FPIR to i. v. glucose and IAA levels [8]. This hypothesis is based on observations in a small number of highly selective first-degree relatives of diabetic patients, of whom the majority were adults. Other data suggest that the disease process may be less predictable, with only a proportion of those with islet cell-specific autoantibodies, or beta-cell dysfunction, or both, progressing to clinical disease [9].

The "Childhood Diabetes in Finland" study (abbreviated the DiMe study) [6] is a population-based family 
survey which, in contrast to most previous projects of its kind [9-11], includes prospective observation of unaffected siblings from the time of diagnosis of the index case. This design excludes the possible confounding effect of substantial variations in the time of discordance for diabetes between the first-degree relative and the proband. At least in identical twins, the likelihood of subsequent clinical diabetes decreases with greater duration of this discordance [12].

An increased understanding of the natural history of preclinical IDDM could facilitate the development of effective strategies for secondary prevention of the disease. This prospective study was undertaken to characterize those high risk siblings who later present with diabetes in relation to those who remain non-diabetic and to learn more about the natural history of the preclinical period.

\section{Subjects and methods}

The population comprised all 57 siblings who tested positive for ICA or IAA, or both, in their initial blood sample taken within 6 months (median 2 weeks) after the diagnosis of the index case in the DiMe study, the background and design of which have been described elsewhere [6]. Briefly the study was initiated at the beginning of September 1986 and all newly diagnosed diabetic children younger than 15 years, their 3 - to 19 -year-old siblings and their parents were invited to join. Informed consent was obtained from the subjects and their parents. The ethical committees of all participating hospitals approved the study protocol. The recruitment of new cases terminated at the end of April 1989. During that period of 32 months, 801 eligible cases were diagnosed, of whom $750(93.9 \%)$ joined the study. Their mean age was 8.5 (2.9; SD) years (range 0.8-14.9 years). Of a total 808 unaffected siblings aged 3-19 years 711 siblings $(88.0 \%)$ as well as an additional 19 siblings younger than 3 years agreed to give a blood sample on at least one occasion. At the time of diagnosis there were 273 - to 19-year-old diabetic siblings $(3.2 \%)$, who were not invited to participate in the study. Thus a total of 730 siblings gave their initial blood sample within 6 months of the diagnosis of the index case, of whom 629 $(86.2 \%)$ were sampled within the first 3 weeks. Forty-six siblings $(6.3 \%)$ were found to be positive for conventional ICA, five $(0.7 \%)$ for IAA only and six $(0.8 \%)$ for both. Of the 52 siblings positive for conventional ICA 31 (4.3\% of the total number of siblings) also had complement-fixing ability. The majority of the siblings positive for ICA and/or IAA were girls $(n=33,57.9 \%)$. The mean age of the subjects was $9.1(4.0 ; \mathrm{SD})$ years and the range varied from 1.1 to 18.9 years. The 57 siblings came from 52 families. Two girls were half-sisters of their respective proband.

All 57 siblings were observed from the initial sampling to the end of April 1992 unless IDDM was diagnosed before that date. Observation of those siblings who contracted the disease ended at diagnosis. The diagnosis was based on (a) clinical symptoms and an increased random blood glucose concentration ( $>10 \mathrm{mmol} / \mathrm{l}$ ) or (b) an elevated fasting $(>6.7 \mathrm{mmol} / \mathrm{l})$ or random blood glucose level $(>10 \mathrm{mmol} / \mathrm{l})$ on two occasions in the absence of symptoms [13]. The median observation period was 46.5 months, ranging from 0.5 to 69 months. Blood samples were obtained at 6-month intervals over the first 2 years and at 12 month intervals thereafter. All 57 siblings were invited for sequential IVGTTs at 6-month intervals over the initial 2 years and at 12 -month intervals thereafter. Forty-four of the 57 siblings
(77\%) participated in at least one IVGTT. A total number of 162 tests were performed on these 44 siblings, giving an individual median of four tests (range 1-8). The median observation period was 8.5 months (range 1.5-30 months) at the time of the first IVGTT, 15 months (range 3.5-36 months) at the second test, 21 months (range 14.5-50 months) at the third and 30 months (range 20.5-60 months) at the fourth test.

ICA were determined by a standard immunofluorescence method from sections of frozen human group O pancreas [14]. The antibodies were identified by both the conventional indirect method and the complement fixation test. Fluorescein-conjugated rabbit anti-human IgG or rabbit anti-human C3c (Behringwerke, Marburg, Germany) was used to detect ICA. Endpoint dilution titres were examined for the positive samples and the results were expressed in JDF units for conventional ICA relative to an international reference standard [15]. The detection limit was $2.5 \mathrm{JDF}$ units. The titres of the complement-fixing ICA were converted into JDF units with a standard curve based on the international reference standard used for conventional ICA with the assumption of a complement-fixing ICA level of 80 JDF units in the undiluted reference serum. The detection limit was $10 \mathrm{JDF}$ units for complement-fixing antibodies. Our laboratory has participated in the international workshops on standardization of the ICA assay, in which its sensitivity was $100 \%$, specificity $98 \%$, validity $98 \%$ and consistency $98 \%$ in the fourth round. IAA were measured by a modification of the liquid phase radioimmunoassay originally described by Palmer et al. [16], the serum samples being extracted with acid charcoal before the assay to remove insulin. Of the extracted serum $80 \mu \mathrm{l}$ was incubated with mono- ${ }^{125}$ I(TyrA14) human insulin (specific activity 200-300 mCi/mg; Novo Research Institute, Bagsvaerd, Denmark) for $20 \mathrm{~h}$. Free and bound insulin fractions were separated using polyethylene glycol, and the results were expressed in terms of bound radioactivity in the precipitate as a percentage of the total count in the assay. The intra-assay coefficient of variation was less than $5 \%$ and the inter-assay variation less than $8 \%$ for IAA levels between $3-10 \%$. The mean (SD) value for the binding of monoiodinated human insulin in 100 non-diabetic subjects was $1.56(0.28) \%$. A sibling was considered to be positive for IAA if insulin binding exceeded $2.4 \%$ (mean +3 SD for the non-diabetic population). Our laboratory has been participating in international workshops on standardization of IAA assays and in the proficiency testing programme for several years and achieved a sensitivity of $78 \%$, a specificity of $100 \%$, a validity of $92 \%$ and a consistency of $100 \%$ in the first proficiency testing programme. The IVGTTs were performed as follows: the recommended duration of the preceding fast was $10-16 \mathrm{~h}$ and the glucose dose $0.5 \mathrm{~g} / \mathrm{kg}$. The duration of glucose infusion was close to 3 min ( $\pm 15 \mathrm{~s}$ ). Blood samples were taken before glucose infusion ( 0 min) and 1,3,6,10,20,30,40,50 and 60 min after it had ended. Blood glucose concentrations were measured by the glucose oxidase method [17]. Serum insulin levels were analysed radioimmunologically [18]. The FPIR was evaluated by (a) the sum of serum immunoreactive insulin concentrations at 1 and 3 min and (b) the area under the curve for insulin for the first 10 min. The intra-individual coefficient of variation for FPIR $(1+3 \mathrm{~min})$ was found to be $24 \%$ in 10 non-diabetic siblings negative for ICA and IAA who underwent four sequential IVGTTs with an interval of 4-8 months.

\section{Statistical analysis}

The results were evaluated statistically by cross-tabulation with chi-square statistics for distributions; in the case of normally distributed variables linear regression analysis $(r)$ for correlation 
Table 1. Clinical, autoimmune and metabolic characteristics at initial screening of those siblings who progressed to clinical IDDM (converters) and of those who remained non-diabetic

\begin{tabular}{|c|c|c|}
\hline & $\begin{array}{l}\text { Converters } \\
(n=17)\end{array}$ & $\begin{array}{l}\text { Non-diabetic } \\
(n=40)\end{array}$ \\
\hline Sex (male/female) & $7 / 10$ & $17 / 23$ \\
\hline Age (years) & $7.1 \pm 0.7$ & $9.8 \pm 0.7^{*}$ \\
\hline $\begin{array}{l}\text { ICA (JDF units) } \\
\text { Conventional } \\
\text { Complement-fixing }\end{array}$ & $\begin{array}{l}160(10-320) \\
40(0-320)\end{array}$ & $\begin{array}{l}10(0-640)^{* *} \\
0(0-640)^{*}\end{array}$ \\
\hline IAA (\% insulin binding) & $1.5(1.2-4.1)$ & $1.6(1.2-14.4)$ \\
\hline $\begin{array}{l}\text { FPIR: } \\
\text { Sum of insulin } \\
\text { at } 1 \text { and } 3 \min (\mathrm{mU} / 1)\end{array}$ & $\begin{array}{l}35.8 \pm 7.1 \\
(n=13)\end{array}$ & $\begin{array}{l}97.2 \pm 10.1 * * * \\
(n=31)\end{array}$ \\
\hline $\begin{array}{l}\text { Area under the } \\
\text { curve } 0-10 \mathrm{~min}(\mathrm{mU} / \mathrm{l} \cdot \mathrm{min})\end{array}$ & $\begin{array}{l}99.1 \pm 29.3 \\
(n=13)\end{array}$ & $\begin{array}{l}307.6 \pm 37.0^{* * *} \\
(n=31)\end{array}$ \\
\hline $\begin{array}{l}\text { Glucose elimination rate } \\
(\% / \mathrm{min})\end{array}$ & $1.69 \pm 0.26$ & $1.88 \pm 0.13$ \\
\hline
\end{tabular}

Values are shown as either mean \pm SEM or medians (range). $* P<0.05 ; * * P<0.01 ; * * * P<0.001$

analyses, Student's unpaired $t$-test for comparisons between two groups and one-way analysis of variance for repeated measures for comparing FPIRs and glucose elimination rates over time within a group and in the case of unequally distributed variables Spearman's non-parametric correlation analysis $\left(r_{\mathrm{s}}\right)$, the MannWhitney $U$ test for comparisons between two groups and the Kruskall-Wallis one-way analysis of variance for comparing ICA and IAA levels at various time points within one group. Multiple regression analysis was used to identify factors explaining the variation in the duration of time to diagnosis.

\section{Results}

By the end of April 1992, 17 siblings (29.8\%) from 16 families had presented with clinical signs of IDDM, the observed duration of the preclinical period ranging from 0.5 to 51 months (median 29 months). Their mean age at the time of diagnosis was 9.3 (3.8) years (range 3.1-15.2 years). Fifteen converters came from families where the index case was the first diabetic individual, while one had in addition a father with IDDM and another, two diabetic siblings at the diagnosis of the proband. There was no difference in sex distribution between the converters and the remaining non-diabetic children, but the former were significantly younger (Table 1) and had higher levels of both conventional and complement-fixing ICA at initial screening. In addition, they had a significantly reduced FPIR in their initial IVGTT. There was no difference between the two groups in the initial IAA levels or glucose elimination rates (Table 1$)$. Two of the 673 siblings $(0.3 \%)$ initially negative for ICA and IAA progressed to clinical diabetes by the end of April 1992.

Of the 33 siblings who initially had conventional ICA of 20 JDF units or more (48.5\%) 16 presented with IDDM during the observation period. Increasing
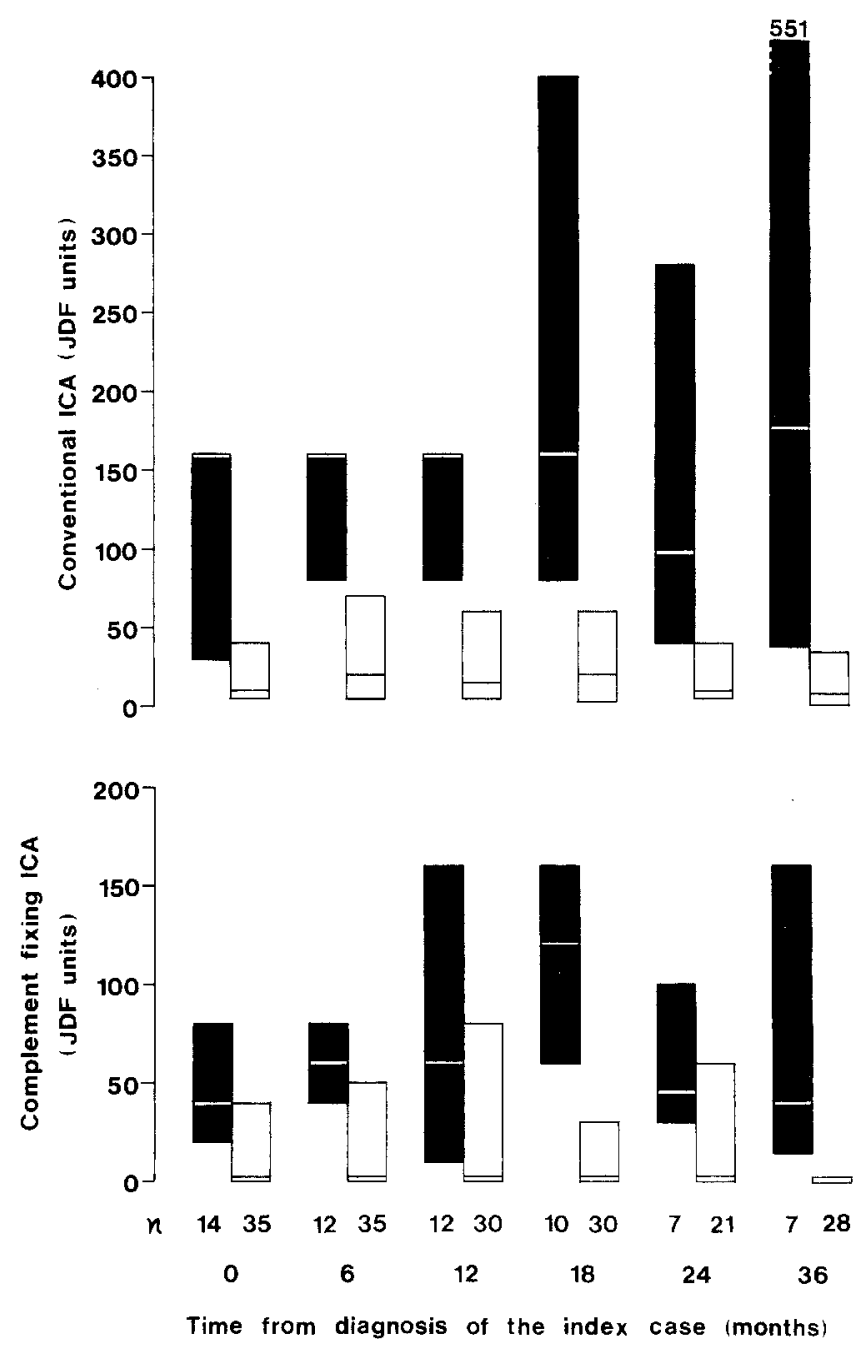

Fig. 1. Conventional and complement-fixing ICA in those siblings who progressed to IDDM ( $\mathbf{\square}$ ) and those who remained non-diabetic $(\square)$ during the observation period. The results are expressed as box plots: the horizontal line within each box denotes the median, while the upper and lower ends mark the 75 th and 25 th percentiles respectively. The converters had higher levels of both conventional ( $P<0.01$ or less) and complement-fixing $(P<0.05$ or less $)$ ICA than the non-diabetic siblings on all occasions. The levels of complement-fixing ICA were higher at 18 months than at the beginning in the converters $(P<0.05)$ The number of subjects $(n)$ in each group at various points is indicated below the lower panel

the cut-off level to 80 JDF units or more resulted in 13 of 22 siblings (59.1\%) presenting with IDDM. All nine siblings with an initial FPIR (sum of insulin at 1 and $3 \mathrm{~min}$ ) lower than $35 \mathrm{mU} / \mathrm{l}$ progressed to clinical disease, as did seven of $13(53.9 \%)$ siblings with an initially retarded glucose elimination rate.

The converters had significantly higher levels of conventional ICA than the non-diabetic siblings on all subsequent occasions (Fig. 1), and no significant change could be observed in these antibody levels with time in either group. The levels of complement-fixing ICA were also higher in the converters at all time points tested (Fig. 1) and increased significantly from their initial 

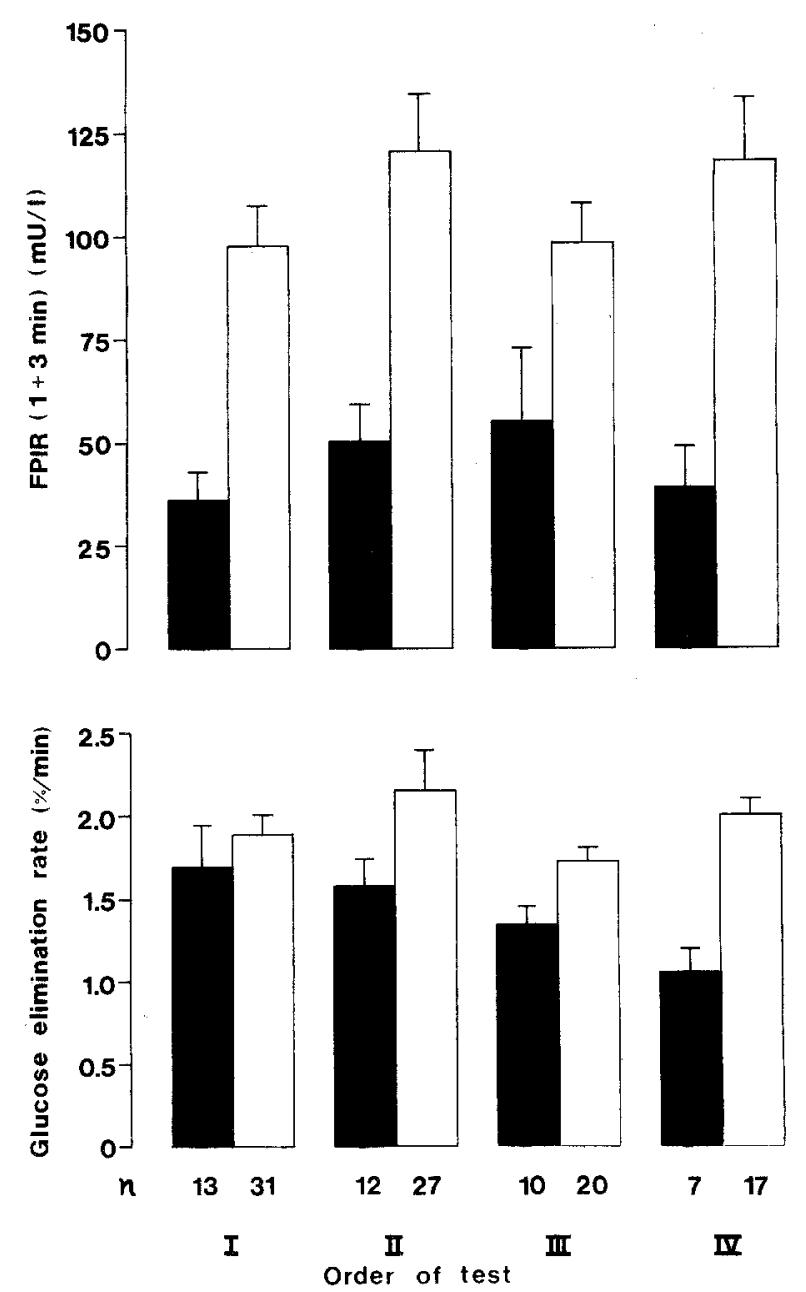

Fig. 2. First phase insulin response (FPIR) and glucose elimination rate in four sequential IVGTTs in those siblings who progressed to clinical IDDM ( $)$ and those who remained nondiabetic $(\square)$. The results are given as mean \pm SEM. The FPIR is expressed as the sum of insulin at 1 and $3 \mathrm{~min}$. The converters had a lower FPIR $(P<0.05$ or less $)$ on all occasions than the nondiabetic siblings and a slower glucose elimination rate in the third $(P<0.01)$ and fourth tests $(P<0.001)$. The number of subjects $(n)$ in each group at various points is indicated below the lower panel

level up to 18 months among the converters. No significant differences could be seen in the concentrations of IAA between the two groups over the first 2 years, but at 3 years the converters had significantly higher levels [median $2.41 \%$ (interquartile range $1.67-3.83 \%$ ) vs $1.85 \%(1.45-2.05 \%) ; P<0.05]$ and showed a significant increase in IAA binding over the first 3 years [from a median of $1.50 \%$ (interquartile range $1.40-1.80 \%$ ) to $2.41 \%$ (interquartile range $1.67-3.83 \%$ ); $P<0.01$.

The converters had a lower FPIR than the siblings who remained non-diabetic in all tests. When the evaluation was based on the sum of insulin at 1 and 3 min (Fig. 2) no further reduction could be seen with time, while the area under the curve increased initially significantly from the first test to the second one, but decreased in the fourth test to a level even lower than in the first test (Fig. 3). The glucose elimination rate de-

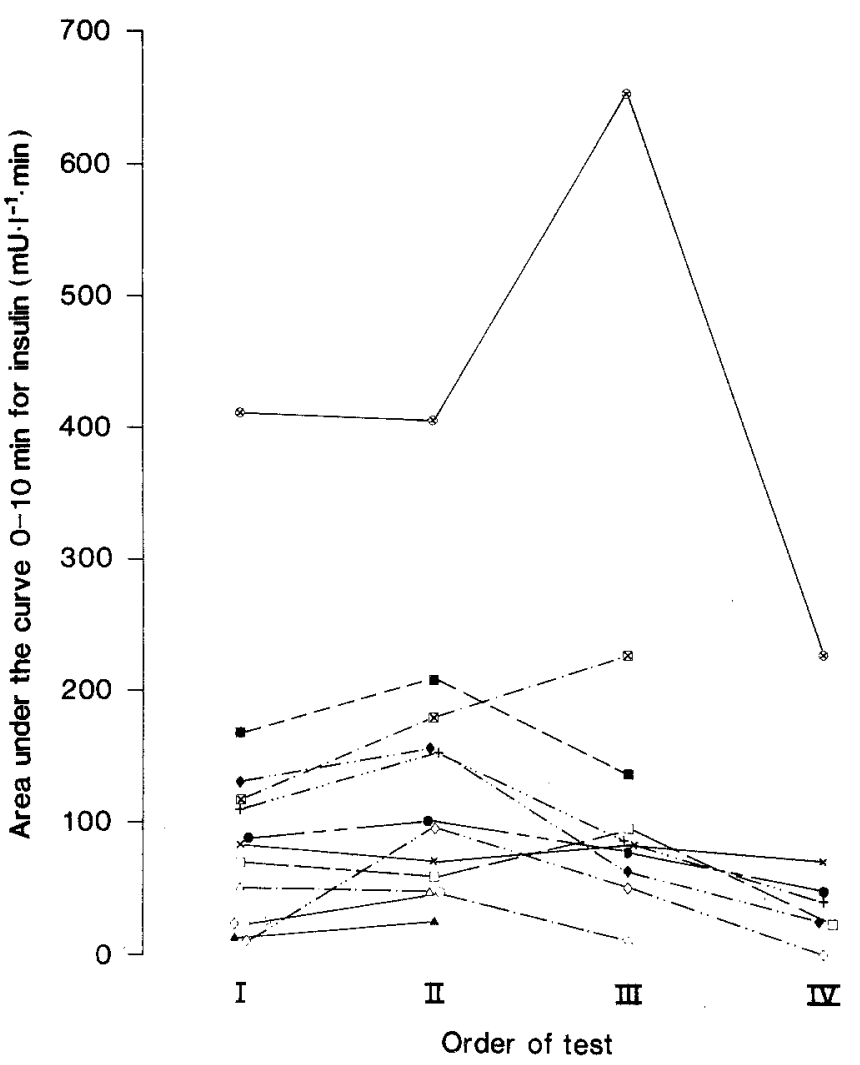

Fig.3. Individual FPIRs expressed as the area under the curve for the first $10 \mathrm{~min}$ in 13 siblings who manifested IDDM during the observation period. The subject with the highest FPIR on all occasions was an initially 10 -year-old obese boy with a relative weight of $151 \% . P<0.05$ for I vs II, I vs IV and II vs IV

creased significantly with time in the converters (Fig. 2), whereas it remained unchanged in the nondiabetic siblings. This resulted in reduced values in the converters in the third and fourth IVGTTs.

No significant correlation could be observed between the duration of the preclinical period, the FPIR and IAA levels at the first screening $(r=0.27$, NS) when the dual parameter model [8] for predicting the time to diagnosis was tested retrospectively in all 13 siblings who had been evaluated for both variables in the preclinical period and later presented with the disease. No meaningful and statistically significant predictive model could be developed for the converters. The duration of the disease-free follow-up period for the entire group was inversely related to initial levels of conventional ICA $\left(r_{\mathrm{s}}=-0.36 ; P<0.01\right)$ and IAA $\left(r_{\mathrm{s}}=-0.28\right.$; $P<0.05)$. There was a positive correlation between the duration of this period and the initial early insulin response $\left(r_{\mathrm{s}}=0.32 ; P<0.05\right)$.

\section{Discussion}

The present data demonstrate that close to one-third of the ICA and/or IAA positive siblings of children with IDDM will present with the disease within 4 years of 
the diagnosis of the index case, and that younger high risk siblings seem to have a greater risk of contracting the disease than older ones. This latter observation may be due to the relatively short observation period so far, since there are indications that younger children progressing to clinical diabetes have an accelerated and more aggressive process of beta-cell destruction than older children and young adults [19-21]. Thus our study series may include some older siblings who may later develop manifest IDDM.

Our observations support the findings of previous family surveys that persistently high ICA levels are strong predictive markers of future IDDM among firstdegree relatives $[7,10,11,22]$, since about half of the siblings with initial conventional ICA of $20 \mathrm{JDF}$ units or more progressed to clinical disease during the observation period. Also a significant increase in the levels of complement-fixing ICA could be observed in the converters over the first 18 months, possibly reflecting augmented islet-cell specific autoimmunity. In agreement with the findings of Thivolet et al. [22], IAA seem to add little to the predictive value of ICA. Of six siblings initially positive for both ICA and IAA three $(50 \%)$ contracted diabetes, a proportion which was not significantly different from that found in the exclusively ICA positive siblings, 14 of $46(30.4 \%)$, while none of the five siblings who had only IAA presented with disease. The increase in IAA levels seen in the converters after observation for 3 years supports the view that these autoantibodies appear relatively late in the preclinical period [23].

A reduced early insulin response to i.v. glucose has been found to be a strong predictive marker of IDDM in first-degree relatives [7,24], especially in children [25]. The present data confirm the predictive power of a decreased FPIR by showing a positive predictive value of $100 \%$ for an initial first phase response lower than $35 \mathrm{mU} / \mathrm{l}$, when based on the sum of insulin at 1 and $3 \mathrm{~min}$. In addition the converters had a lower early insulin response in the first test compared to those who remained non-diabetic. The FPIR was not significantly related to the time to diagnosis in the converters, however, and could accordingly not be used to predict the duration of the preclinical period, as suggested in some previous reports $[8,24]$.

No further decrease in the initially reduced early insulin response could be observed with time in the converters as a group, when expressed as the sum of insulin at 1 and $3 \mathrm{~min}$. Several individuals showed a considerable fluctuation in their response during the preclinical period, with transient reversal of the reduced initial response to a low normal value in some subjects. When the early insulin response was expressed as the area under the curve for the first $10 \mathrm{~min}$ there was initially an increase in the converters followed by a reduction, whereas no significant changes could be seen in the non-diabetic siblings. The longest interval between the observation of a reduced early insulin response and clinical manifestation of IDDM was 48 months. These observations are compatible with the hypothesis of multiple impacts on the beta cells resulting in a destructive process that progresses step-by-step towards ultimate total beta-cell loss [26]. The results do not support the idea of a linearly progressive beta-cell destruction.

No significant difference in the glucose elimination rate was observed between the converters and the nondiabetic siblings in the initial IVGTT. This indicates that the converters had normal glucose tolerance at this stage, but experienced a decrease in glucose elimination rate with time resulting in significantly retarded elimination from the third test onwards. This implies that glucose intolerance is a late phenomenon in the preclinical process.

A clinically rational predictive model for IDDM proved unattainable in the present population despite considerable efforts to develop such a model. The application of the dual parameter model [8] resulted in a poor prediction of the time to diagnosis of diabetes. The relationships between the duration of the diseasefree period, the initial levels of ICA and IAA and the initial FPIR were relatively weak and could only explain a small proportion of the variation in the length of this period. This indicates that the natural history of preclinical diabetes comprises a wide spectrum of individual disease processes even in high risk first-degree relatives. This may complicate the identification of those progressing to clinical disease at a stage when their insulin secreting capacity is still adequate for maintaining normoglycaemia.

The extent to which observations made in first-degree relatives of diabetic subjects can be applied to the vast majority of sporadic cases has been questioned, since only $10-20 \%$ of newly-diagnosed diabetic children have another family member with IDDM [27, 28]. On the other hand, there are no indications that the pathogenesis of familial IDDM should differ from the process in sporadic disease, although familial cases have been shown to have milder metabolic derangements and a better preserved beta-cell function at diagnosis than the sporadic ones [28]. This is probably due to higher awareness of diabetic symptoms and consequently an earlier hospitalization in familial cases.

In conclusion, progression to clinical IDDM in high risk siblings is associated with young age, high and increasing ICA levels, increased IAA binding, reduced insulin secretion and deteriorating glucose tolerance. None of these characteristics discriminates completely between the siblings who presented with clinical disease and those who remained non-diabetic, however. This may reflect substantial individual variation in the disease process and may imply that linearly progressive beta-cell destruction is the exception rather than a common phenomenon in preclinical IDDM.

Acknowledgements. This work was supported by grants from the Juvenile Diabetes Foundation, USA (grant 188517), the Associ- 
ation of Finnish Life Insurance Companies, the Sigrid Jusélius Foundation, the National Institutes of Health (Bethesda, Md., USA; grant DK-37957), the University of Helsinki, the Nordisk Insulin Foundation and Novo-Nordisk A/S, Denmark. We are grateful to all the participating family members and the hospitals and their staff. We thank Ms. S. Anttila, Ms. T.Halonen, Ms. R. Päkkilä, Ms. M. Rissanen and Ms. P. Ronkainen for their skillful technical assistance and Professor E. Gale for valuable comments.

The Childhood Diabetes in Finland (DiMe) Study Group is composed of the following members:

Principal investigators: H. K. Åkerblom, J. Tuomilehto

Coordinators: R. Lounamaa, L. Toivanen

Data management: E. Virtala, J.Pitkäniemi

Local investigators: A.Fagerlund, M. Flittner, B. Gustafsson, C. Häggquist, A. Hakulinen, L. Herva, P. Hiltunen, T. Huhtamäki, N-P. Huttunen, T. Huupponen, M.Hyttinen, T. Joki, R. Jokisalo, M-L. Käär, S.Kallio, E.A.Kaprio, U.Kaski, M.Knip, L.Laine, J.Lappalainen, J.Mäenpää, A-L. Mäkelä, K.Niemi, A. Niiranen, A. Nuuja, P. Ojajärvi, T. Otonkoski, K. Pihlajamäki, S. Pöntynen, J. Rajantie, J. Sankala, J. Schumacher, M. Sillanpää, M-R. Ståhlberg, C-H. Stråhlmann, T. Uotila, M. Väre, P. Varimo, G. Wetterstrand

Special investigators: A.Aro, H.Hurme, H. Höyty, J.Ilonen, J. Karjalainen, M. Knip, P. Leinikki, A. Miettinen, L. Räsänen, A. Reunanen, E. Savilahti, E. Tuomilehto-Wolf, S. M. Virtanen

\section{References}

1. Eisenbarth GS (1986) Type 1 diabetes: a chronic autoimmune disease. N Engl J Med 314: 1360-1368

2. Bonifacio E, Bottazzo GF (1991) Immunology of IDDM (type 1 diabetes) - Entering the ' 90 s. In: Alberti KGMM, Krall LP (eds) Diabetes annual/6.Elsevier, Amsterdam, pp 20-47

3. Bennett PH (1990) Epidemiology of diabetes mellitus. In: Rifkin H, Porte D Jr (eds) Diabetes mellitus, theory and practice. Elsevier, New York pp 357-377

4. Krolewski AS, Warram J, Rand LI, Kahn CR (1987) Epidemiologic approach to the etiology of type 1 diabetes and its complications. N Engl J Med 317: 1390-1397

5. Reunanen A, Åkerblom HK, Käär M-L (1982) Prevalence and ten year (1970-79) incidence of insulin-dependent diabetes mellitus in children and adolescents in Finland. Acta Paediatr Scand 71: 893-899

6. Tuomilehto J, Lounamaa R, Tuomilehto-Wolf E et al. (1992) Epidemiology of childhood diabetes mellitus in Finland background of a nationwide study of type 1 (insulin-dependent) diabetes mellitus. Diabetologia 35:70-76

7. Srikanta S, Ganda OP, Rabizadeh A, Soeldner JS, Eisenbarth GS (1985) First-degree relatives of patients with type 1 diabetes mellitus: islet cell antibodies and abnormal insulin secretion. N Engl J Med 313: 461-464

8. Ziegler R, Jackson RA, Ziegler AG, Eisenbarth GS (1990) Type 1 diabetes: polygenic inheritance, multiple autoantigens and "dual" parameter prediction. J Autoimmun 3 [Suppl 1]: 69-74

9. McCulloch DK, Klaff LJ, Kahn SE et al. (1990) Nonprogression of subclinical $\beta$-cell dysfunction among first-degree relatives of IDDM patients: 5-yr follow-up of the Seattle family study. Diabetes 39: 549-556

10. Bonifacio E, Bingley PJ, Shattock Met al. (1990) Quantification of islet-cell antibodies and prediction of insulin-dependent diabetes. Lancet I: 147-149
11. Riley WJ, Maclaren NK, Krischer J et al. (1990) A prospective study of the development of diabetes in relatives of patients with insulin-dependent diabetes. N Engl J Med 323: 1167-1172

12. Olmos P, A'Hern R, Heaton DA et al. (1988) The significance of the concordance rate for type 1 (insulin-dependent) diabetes in identical twins. Diabetologia 31: 747-750

13. WHO Study Group (1985) Diabetes mellitus. Technical Report Series 727. World Health Organisation, Geneva, pp 1012

14. Bottazzo GF, Dean BM, Gorsuch AN, Cudworth AG, Doniach D (1980) Complement-fixing islet cell antibodies in type 1 diabetes: possible monitors of active beta-cell damage. Lancet I: 668-672

15. Lernmark $\AA$, Molenaar JL, van Beers WAM et al. (1991) The fourth international serum exchange workshop to standardize cytoplasmicislet cell antibodies. Diabetologia 34: 534-535

16. Palmer JP, Asplin CM, Clemons P et al. (1983) Insulin antibodies in insulin-dependent diabetics before insulin treatment. Science 222: 1337-1339

17. Hjelm M (1966) Enzymatic determination of hexoses in blood and urine. Scand J Clin Lab Invest 192 [Suppl]: 85 -98

18. Herbert V, Lau KS, Gottlieb CW, Bleicher SJ (1965) Coated charcoal immunoassay of insulin. J Clin Endocrinol 25: 1375 1384

19. Knip M, Ilonen J, Mustonen A, Åkerblom HK (1986) Evidence of an accelerated B-cell destruction in HLA Dw3/Dw4 heterozygotes with type 1 (insulin-dependent) diabetes. Diabetologia $29: 347-351$

20. Maclaren NK (1988) How, when and why to predict IDDM. Diabetes 37: 1591-1594

21. Karjalainen J, Salmela P, Ilonen J, Surcel HM, Knip M (1989) A comparison of childhood and adult type 1 diabetes mellitus. N Engl J Med 320: 881-886

22. Thivolet C, Beaufrère B, Gebuhrer L, Chatelain P, Orgiazzi J, François R (1991) Autoantibodies and genetic factors associated with the development of type 1 (insulin-dependent) diabetes mellitus in first degree relatives of diabetic patients. Diabetologia 34: 186-191

23. McEvoy RC, Witt ME, Ginsberg-Fellner F, Rubinstein P (1986) Anti-insulin antibodies in children with type 1 diabetes mellitus: genetic regulation of production and presence at diagnosis before insulin replacement. Diabetes 35: 634-641

24. Vardi P, Crisa L, Jackson RA et al. (1991) Predictive value of intravenous glucose tolerance test insulin secretion less than or greater than the first percentile in islet cell antibody positive relatives of type 1 (insulin-dependent) diabetic patients. Diabetologia 34: 93-102

25. Chase HP, Voss MA, Butter-Simon N, Hoops S, O'Brien D, Dobersen MJ (1987) Diagnosis of pre-type 1 diabetes. J Pediatr 111: 807-812

26. Nerup J, Mandrup-Poulsen T, Molvig J,Helqvist S, Wogensen L, Egeberg J (1988) Mechanisms of pancreatic $\beta$-cell destruction in type 1 diabetes. Diabetes Care 11 [Suppl 1]: 16-23

27. Dahlquist G, Blom L, Tuvemo T, Nyström L, Sandström A, Wall S (1989) The Swedish childhood diabetes study - Results from a nine year case register and a one year case-referent study indicating that type 1 (insulin-dependent) diabetes mellitus is associated with both type 2 (non-insulin-dependent) diabetes mellitus and autoimmune disorders. Diabetologia 32: 2-6

28. Knip M, Penttilä P, Karjalainen J, Lounamaa R, Ảkerblom HK and the Study Group on Childhood Diabetes in Finland (1991) Clinical presentation and autoimmune markers in familial cases with IDDM (abstract). Diabetes 40 [Suppl 1]: $279 \mathrm{~A}$ 